RESEARCH ARTICLE

\title{
Gastrointestinal parasites of dogs in Hantana area in the Kandy District $^{\dagger}$
}

\author{
P.K. Perera ${ }^{1}$, R.P.V.J. Rajapakse ${ }^{2}$ and R.S. Rajakaruna ${ }^{1^{*}}$ \\ ${ }^{1}$ Department of Zoology, Faculty of Science, University of Peradeniya, Peradeniya. \\ ${ }^{2}$ Department of Veterinary Pathobiology, Faculty of Veterinary Medicine and Animal Sciences, University of Peradeniya, Peradeniya.
}

\begin{abstract}
Gastrointestinal parasites cause serious illness in dogs, and some of these infections are zoonoses. Faecal samples were collected from domestic, semi-domestic and stray dogs in Hantana area to determine the prevalence, intensity and types of gastrointestinal (GI) parasites. The samples were processed by modified salt floatation, Sheather's sucrose floatation and direct iodine mounts followed by morphological identification. Of the 90 dogs examined, $81(90.0 \%)$ were infected with one or more GI parasites. Mixed infections were more common $(72.8 \%)$ than single infections $(27.2 \%)$. Although there was no significant difference in the prevalence of infections among the three dog categories (chi square, $\mathrm{p}>0.05$ ), less intensity of infections and a fewer number of parasite species were found in domestic dogs. Of the 13 parasite species found, 11 were zoonotic, Ancylostoma sp., being the most prevalent (73.3 \%) followed by Toxocara canis $(27.8 \%)$ and Spirocerca lupi $(22.2 \%)$. The other zoonotic species recorded were Entamoeba sp., Toxascaris sp., Trichuris vulpis, Blastocystis sp., Strongyloides sp., Isospora sp., Capillaria aerophyla and Giardia sp., thus the prevalence of zoonotic infections in the dog population poses a threat to the people living in Hantana area. Although Toxascaris leonina was previously recorded in leopards in Kandy, this was the first record of Toxascaris sp. from dogs in Sri Lanka. The fewer helminth infections and species diversity in domestic dogs can be due to the use of broad scale antihelminthics. Regular deworming with specific antihelminthics and anti-protozoan treatments after faecal examinations should be carried out. Of the three methods used, floatation method was more reliable in recovering eggs and cysts of helminths while iodine smears were effective against protozoans. However, using a combination of methods increased the likelihood of diagnosing as many parasites as possible.
\end{abstract}

Keywords: Domestic, helminths, protozoans, semi-domestic dogs, stray, zoonoses.

\section{INTRODUCTION}

Gastrointestinal (GI) parasites are found in dogs worldwide but are more prevalent in the tropics and subtropics especially in developing countries where the communities are socioeconomically challenged. Protozoans and helminths are among the most common GI parasites encountered and is one of the main causes of mortality in dogs (Bridger \& Whitney, 2009). Many studies have been conducted around the world to investigate the prevalence of GI parasites in dogs such as in Hungary (Fok et al., 2001), South Africa (Minnaar et al., 2002), India (Traub et al., 2002), Venezuela (Ramı'rez-Barrios et al., 2004), Japan (Asano et al., 2004), Mexico (Egu1'aAguilar et al., 2005) and Pakistan (Chattha et al., 2009) reporting many helminth and protozoan infections with zoonotic potential with high prevalence and heavy worm burden in developing countries.

Dogs have close contact with humans and this represents a serious potential source of direct transmission of parasites from dogs to humans (Itoh et al., 2009). Dogs act as reservoirs of many parasites of zoonotic potential such as Taenia sp., hydatid tapeworm (Echinococcus sp.), Diphylidium caninum, dog roundworm (Toxocara canis), dog hookworm (Ancylostoma sp.), Giardia sp., and Cryptosporidium sp. (Abo-Shehada \& Ziyadeh, 1991; Anene et al., 1996; Hackett \& Lappin, 2003; Soriano, 2010). Therefore food and water contaminated with dog faeces and dog meat serve as the major sources involved in the intake of GI zoonotic parasites via oral route into the humans.

\footnotetext{
*Corresponding author (rupikar@pdn.ac.lk)

$\dagger$ Preliminary observations of this study have been presented at the annual sessions of the Sri Lanka Association for the Advancement of Science, 2011.
} 
Although most protozoan and helminth species frequently found in the GI tracts of dogs are cosmopolitan, the prevalence varies considerably from one region to another (Oliveira-Sequeira et al., 2002). The factors that affect the prevalence of the parasites include age, breed, gender of the dog, living conditions, animal density, neutering status, nutritional status, anthelmintic treatments, immune status, owner's social status and the techniques used in diagnosing infections (Bugg et al., 1999; OliveiraSequeira et al., 2002; Scaramozzino et al., 2009). Other factors such as provenance (Bugg et al., 1999), role (Habluetzel et al., 2003), raw meat feeding (Stallbaumer, 1987), and seasonality (Bianciardi et al., 2004) have also been studied. In addition to the above, stress (Capelli et $a l ., 2003$ ) and geographical location may also influence the prevalence of GI parasites (Robertson et al., 2000; Kagira \& Kanyari, 2001).

There is a large dog population in Sri Lanka with a dog to human ratio of 1:8 (De Alwis, 2000). The most commonly found Gl parasites in dogs in Sri Lanka are helminths like D. caninum, T. canis and Ancylostoma caninum, and protozoans like Toxoplasma gondii, Giardia canis and Entamoeba histolytica. Among those recorded from Sri Lanka, T. gondii, Echinococcus granuloses, A. caninum, A. braziliense, Diphyllobotrium latum and T. canis were known to be zoonoses (Senadhira, 1967a, b; Dissanaike, 1961, 1995). In Sri Lanka, the infection spirocercosis caused by the nematode Spirocerca lupi have been recorded as widespread during the 1960s (Seneviratna, 1962), which is fatal as infected dogs can manifest death due to aortic rupture (Seneviratna, 1962; Seneviratne et al., 1965). There is no current literature available, on the nature and prevalence of GI parasitic infections in dogs in Sri Lanka, except for a study conducted in Polonnaruwa by De Alwis in 2000. Most of the previous studies of GI parasites of dogs in Sri Lanka date back into the 1960s and 1950s. Although surveys had been carried out, these are restricted to small high risk groups or concerned with particular parasites, and none of this recent work has been published (personal communication). The present study was carried out to determine the prevalence, intensity and types of GI parasites in domestic, semi-domestic and stray dogs in Hantana area in the Kandy District and to assess the risk factors associated with the prevalence of parasitic infections.

\section{METHODS AND MATERIALS}

\section{Study site}

Faecal samples from dogs were collected from Hantana area in the Kandy District (Figure 1). The Hantana mountain range has an elevation ranging from $518 \mathrm{~m}$ to $1100 \mathrm{~m}$. Climatically, Hantana is a tropical humid region with an annual rainfall ranging between 2000-2500 mm and a mean annual temperature of $24^{\circ} \mathrm{C}$. The study area extended from the Institute of Fundamental Studies (IFS), through Hantana Place, the Hantana Housing Scheme including the lower tank division, upper tank division upto the Hantana tea estate $\left(7^{\circ} 16^{\prime}-7^{\circ} 17^{\prime} \mathrm{N}\right.$ and $80^{\circ}$ $\left.37^{\prime}-80^{\circ} 38^{\prime} \mathrm{E}\right)$. Total area of the study is approximately $1.5 \mathrm{~km}^{2}$ with a human population of about 1897 having visible differences in the socioeconomic levels in the community.

\section{Study animals}

Dogs were categorized as domestic, semi-domestic and stray dogs. Domestic dogs were the ones that were kept under a caretaker or a dog owner and that were kenneled

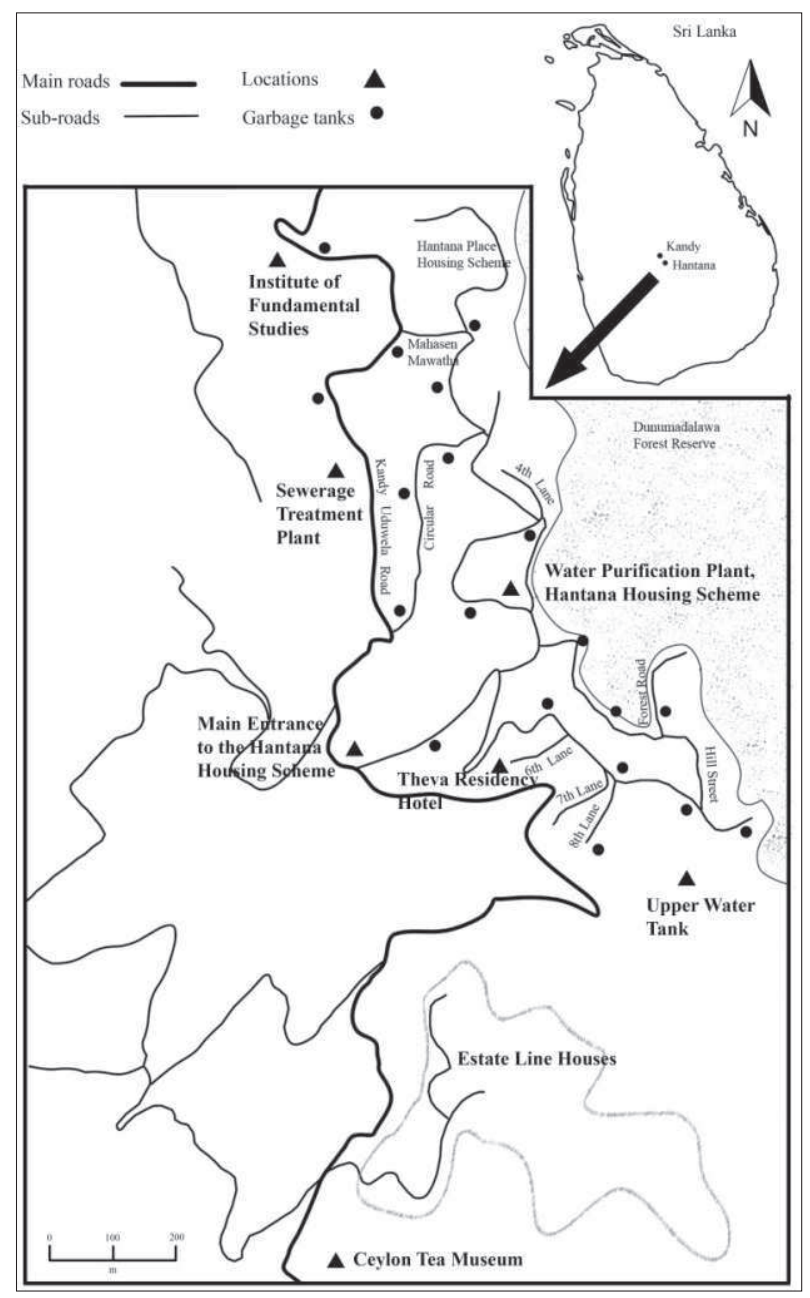

Figure 1: A map showing the study area in Hantana 
or kept in the backyard of the house, vaccinated against rabies and other diseases and de-wormed. The semidomestic dogs were the ones that may or may not have a proper owner, fed by the neighbourhood, may or may not be vaccinated against rabies and not de-wormed. Finally, the stray dogs were the street dogs that were without an owner, not vaccinated against rabies, not been treated for worms and usually fed on garbage. Faecal samples were collected from both male and female dogs at different age groups of all three dog categories. Information about the domestic dogs such as age, sex, locality, details about vaccination and de-worming practices, clinical signs and details about their diet were collected using a questionnaire. Dogs that were de-wormed twice or four times a year were considered as regularly de-wormed while dogs that were de-wormed less than twice a year were considered as not de-wormed regularly. Domestic dogs that mingle with the stray dogs in the neighbourhood were not sampled. Faecal samples of semi-domestic dogs were collected only from an isolated population in the estate line houses. They do not mingle with either the stray dogs or domestic dogs in the Hantana Housing Scheme.

\section{Sample collection}

A total of 90 dogs (assuming $25 \%$ of the domestic dogs and $50 \%$ of the semi-domestic/ stray dogs were infected, at 95 two-sided confidence level power $=80$ ) representing approximately $70 \%$ of the dog population in Hantana (30 dogs per category) were sampled. Fresh faecal samples were collected as soon as the dogs defecated. The samples were collected from June 2010 to March 2011 during 6.00 a.m. to 8.00 a.m. One dog was sampled only once during the study. For stray dogs, either the fresh faecal samples that were found along the roads or the faecal samples soon after defecation were collected. Sampling of stray dogs was done in areas that were clearly marked by stray dogs as their territory near garbage tanks and also well away from the residential areas. Information of the dog such as sex, age (whether a puppy or an adult dog) and locality was recorded when collecting samples from stray dogs. Samples from the domestic dogs were collected with the help from the dog owners. All the samples were brought to the laboratory in a cooler within an hour of collection and were kept at $4{ }^{\circ} \mathrm{C}$ until use.

\section{Faecal analysis}

Faecal samples were analyzed using three methods, namely, modified salt floatation, Sheather's sucrose floatation method and direct iodine smears. Morphological identification was done according to the photo guide and text book "Clinical Parasitology of Dogs" by Dunsmore and Shaw (1990). Eggs of different species were identified and the number of eggs and cysts in $0.5 \mathrm{~mL}$ was estimated and eggs per gram (EPG) of faeces were calculated. Oocyst isolation was done by the Sheather's sucrose floatation method. Length and the width of eggs and cysts were measured under high power $(10 \times 40)$ for morphometric identification.

\section{Modified salt floatation method}

Approximately $3 \mathrm{~g}$ of faeces was measured and was taken into a $50 \mathrm{~mL}$ capped centrifuge tube. The volume was made up to $50 \mathrm{~mL}$ by adding distilled water, and was mixed thoroughly using a wooden applicator. This suspension was centrifuged at $2045 \mathrm{~g}$ for $20 \mathrm{mins}$. The supernatant was discarded and the pellet was washed twice by re-suspending in distilled water followed by two centrifugations until a clear supernatant was obtained. The pellet was then emulsified with saturated salt and was mixed thoroughly. It was centrifuged again for $20 \mathrm{~min}$ at $2045 \mathrm{~g}$. Approximately $5 \mathrm{~mL}$ of the top meniscus was aspirated and added to a $15 \mathrm{~mL}$ centrifuge tube. The total volume was made up to $15 \mathrm{~mL}$ by adding distilled water and centrifuged for $10 \mathrm{~min}$ at $1370 \mathrm{~g}$. This was repeated and finally $1 \mathrm{~mL}$ of the suspension with the pellet was mixed and transferred to a $1.5 \mathrm{~mL}$ eppendorf ${ }^{\circledR}$ microfuge tube using a pasteur pipette. Distilled water was added to make it up to $1.5 \mathrm{~mL}$ and centrifuged for $10 \mathrm{~min}$ at $1150 \mathrm{~g}$ in the microcentrifuge. The supernatant was decanted and the pellet was mixed thoroughly with $0.5 \mathrm{~mL}$ of the supernatant. Microscope slides were prepared using about $0.1 \mathrm{~mL}$ of the suspension and covered with a cover slip without staining. Five smears were observed from each sample under the light microscope. Eggs of different species were identified and the number of eggs and cysts in $0.5 \mathrm{~mL}$ was estimated and eggs per gram (EPG) of faeces were calculated assuming the method had concentrated all the eggs in the $3 \mathrm{~g}$ of faeces into $0.5 \mathrm{~mL}$.

\section{Sheather's sucrose floatation method}

Oocyst isolation was done using Sheather's saturated sucrose as the floatation fluid instead of salt following the same method described under the modified salt flotation method. Number of cysts and eggs of a particular species in each sample was calculated as an EPG value as mentioned above.

\section{Direct saline and iodine smears}

A drop of saline and a drop of iodine solution were placed separately on a glass microscope slide. A small 
portion (size of a match head) of the faecal sample was picked up using a toothpick and was mixed with the drop of saline. This was repeated with the drop of iodine. The two smears were covered with separate cover slips and observed under the light microscope. Eggs and cysts were identified and their relative numbers in a sample size of a match head was estimated.

The length and the width of eggs and cysts isolated were measured using the calibrated eye piece graticule under high power $(10 \times 40)$.

\section{Identification of larvae}

Helminth eggs were cultured and larvae were obtained according to the method described in Rajapakse et al. (1992). Freshly harvested Toxocara and Toxascaris eggs were placed in petri dishes in $0.1 \mathrm{~N}$ sulphuric acid at a depth of $0.5 \mathrm{~cm}$ in room temperature $\left(22-24{ }^{\circ} \mathrm{C}\right)$ to incubate. Embryonated eggs containing infective larvae were washed three times in distilled water by centrifugation at $1150 \mathrm{~g}$ for $10 \mathrm{~min}$ to remove sulphuric acid and other organic matter. One millilitre quantities of the suspension were transferred to five $50 \mathrm{~mL}$ plastic centrifuge tubes. To each tube, $10 \mathrm{~mL}$ of saturated calcium hypochlorite solution at room temperature was added. Every five minutes, one tube with suspension was diluted to $50 \mathrm{~mL}$ with distilled water, in order to prevent any further de-coating action on the egg shell by the calcium hypochlorite solution. Eggs at the butt of each tube were observed under the microscope to select the tube with eggs at the suitable de-coating stage with larvae coming out of eggs. Then the selected tubes were centrifuged at $1150 \mathrm{~g}$ for $10 \mathrm{~min}$. After removal of the supernatant, suspensions were washed ten times $(1150 \mathrm{~g}$ for 10 mins) and the hatched larvae at the butt of the tube were collected.

\section{RESULTS}

\section{Prevalence of parasites}

Of the 90 dogs examined, $81(90.0 \%)$ were infected with one or more GI parasites of nematodes, trematodes and protozoans. Among the three dog categories, the stray dogs had the highest prevalence $(93.3 \%)$ of overall GI infections followed by the semi-domestic dogs $(86.7 \%)$ and the domestic dogs (86.7\%) (Figure 1) but these differences were not statistically significant $(\mathrm{p}>0.05)$. Helminth infections were significantly more common (85.6\%) compared to the protozoan infections (35.6\%); $\left(\chi^{2}=47.099 ; \mathrm{df}=1, \mathrm{p}<0.001\right)$. Domestic dogs had comparatively fewer helminth infections $(76.7 \%)$ than the semi-domestic $(86.7 \%)$ and stray $(93.3 \%)$ dogs but the prevalence of protozoan parasites was higher in domestic dogs $(40.0 \%)$ than in the other two groups $(37.0 \%)$. However, these differences in helminth and protozoan infections in different dog groups were not statistically significant $(p>0.05)$.

Table 1: Prevalence of different parasite species in domestic, semi-domestic and stray dogs in Hantana area $(\mathrm{n}=90)$

\begin{tabular}{llcccc}
\hline & Parasite species & \multicolumn{4}{c}{ Prevalence of infection (\%) } \\
& & Overall & Domestic & $\begin{array}{c}\text { Semi- } \\
\text { domestic }\end{array}$ & Stray \\
\hline \multirow{3}{*}{ Helminths } & & & & & \\
& Ancylostoma sp. & 73.3 & 60.0 & 80.0 & 80.0 \\
& Toxocara canis & 27.8 & 33.3 & 50.0 & 6.7 \\
& Spirocerca lupi & 22.2 & 26.7 & 23.3 & 16.7 \\
& Toxascaris sp. & 12.2 & - & - & 26.7 \\
& Trichuris vulpis & 12.2 & - & - & 36.7 \\
& Strongyloides sp. & 11.1 & - & 20.0 & 13.3 \\
& Capillaria aerophyla & 5.6 & - & - & 16.7 \\
& Trematode eggs & 2.2 & - & 6.7 & - \\
Protozoans & Entamoeba sp. & 17.7 & 76.7 & 66.7 & 33.3 \\
& Blastocystis sp. & 12.2 & 66.7 & 23.3 & 33.3 \\
& Isospora sp. & 7.8 & - & - & 76.7 \\
& Giardia sp. & 2.2 & - & 23.3 & - \\
& Cyclospora sp. & 1.1 & 3.3 & - & - \\
\hline & Total & 90.0 & 93.3 & 86.7 & 86.7 \\
\hline
\end{tabular}


Mixed infections were more common (72.8\%) than single infections $(27.2 \%)$. Percentage of dogs having mixed infections of two, three and four or more parasites were $29.6 \%, 32.1 \%$ and $11.1 \%$, respectively. Mixed infections of helminths were common than those of protozoans. More than half of the dogs $(56.8 \%)$ were concurrently infected with two or more species of helminth parasites where infections of Ancylostoma sp. and Toxocara canis being the most common type (27.1\%). However, mixed infections of protozoans were found only in three dogs $(3.7 \%)$.

\section{Parasite species and intensity}

A total of 13 parasite species were found in dogs in the Hantana area (Table 1). Among them the most common type of infection was by Ancylostoma sp. (73.3\%) followed by Toxocara canis infections $(27.8 \%)$ and S. lupi $(22.2 \%)$. These three parasites were recorded from all the dog categories (Table 1). The least common was the infection by Cyclospora sp. (1.1\%), which was found from a domestic dog aged less than one year (Table 1). All helminth species except $T$. canis and $S$. lupi were higher in stray dogs compared to domestic and semi-domestic dogs (Table 1). Entamoeba sp. (17.7 $\%$ ) was the most prevalent protozoan parasite followed by Blastocystis sp. Other two protozoans Giardia sp. and Isospora sp. were restricted only to semi-domestic dogs and stray dogs, respectively. Stray dogs harboured more parasite species (10) than semi-domestic (8) and domestic dogs (6). All dog categories had three types of protozoans but the number of helminth infections varied as seven types in stray dogs and five in semi-domestic dogs (Table 1).

In the domestic dogs, the intensity of infection was very low compared to the semi-domestic and stray dogs (Table 2). For S. lupi, Toxascaris sp., T. vulpis and $C$. aerophyla, a higher intensity was recorded from stray dogs compared to that from the other two categories.

Table 2: Eggs and cysts of different parasites in the domestic, semi-domestic and stray dogs in Hanatana area

\begin{tabular}{|c|c|c|c|c|c|c|c|}
\hline & \multirow[b]{2}{*}{ Parasite species } & \multirow[b]{2}{*}{$\begin{array}{c}\text { Mean } \\
\text { length } \\
(\mu \mathrm{m})\end{array}$} & \multicolumn{5}{|c|}{${ }^{\dagger}$ Mean EPG or cyst counts } \\
\hline & & & $\begin{array}{l}\text { Mean } \\
\text { width } \\
(\mu \mathrm{m})\end{array}$ & Overall & Domestic & $\begin{array}{c}\text { Semi- } \\
\text { domestic }\end{array}$ & Stray \\
\hline \multirow[t]{8}{*}{ Eggs } & Ancylostoma sp. & 62.5 & 38.8 & 61.5 & 6.3 & 142.3 & 21.2 \\
\hline & Toxocara canis & 69.5 & 63.2 & 17.7 & 0.9 & 29.9 & 4.2 \\
\hline & Spirocerca lupi & 37.5 & 15.0 & 11.6 & 12.3 & 6.8 & 16.1 \\
\hline & Toxascaris sp. & 68.9 & 54.5 & 25.5 & 0 & 0 & 25.5 \\
\hline & Trichuris vulpis & 70.0 & 42.6 & 157.4 & 0 & 0 & 157.4 \\
\hline & Strongyloides sp. & 73.0 & 40.0 & 24.7 & 0 & 32.1 & 7.8 \\
\hline & Capillaria aerophyla & 69.9 & 35.0 & 26.9 & 0 & 0 & 26.9 \\
\hline & Trematode sp. & 87.5 & 40.0 & 0.7 & - & 0.7 & - \\
\hline \multirow[t]{5}{*}{ Cysts } & Entamoeba sp. & 18.2 & 10.0 & 1.3 & 1.2 & 1.4 & 2.7 \\
\hline & Blastocystis sp.* & 10.3 & 8.9 & - & - & - & - \\
\hline & Isospora sp. & 35.8 & 28.8 & 34.9 & - & - & 34.9 \\
\hline & Giardia sp. & 14.0 & 7.8 & 28.0 & - & 28.0 & - \\
\hline & Cyclospora sp. & 10.0 & 7.6 & 0.3 & 0.3 & - & - \\
\hline
\end{tabular}

${ }^{\dagger}$ Note: $\mathrm{EPG}=$ eggs per gram

* Blastocystis was identified only by iodine smears and therefore was unable to get the cyst counts

\section{Comparison of methods}

Modified salt floatation method gave better results in recovering nematode eggs compared to the other two methods (Table 3). Sheather's sucrose floatation method was better in recovering protozoan cysts compared to the modified salt floatation. Iodine smear preparation allowed better detection of protozoan cysts compared to the two floatation methods. Sheather's sucrose floatation method recovered all nematode eggs except those by Spirocerca lupi in less prevalence (16\%). Spirocerca lupi was best recovered by Sheather's sucrose floatation. All protozoans 
Table 3: Comparison of modified salt floatation method, Sheather's sucrose floatation method and direct iodine mounts

\begin{tabular}{llccc}
\hline \multirow{6}{*}{ Helminths } & Parasite species & $\begin{array}{c}\text { Percentage prevalence (\%) } \\
\text { Modified } \\
\text { salt } \\
\text { floatation } \\
\text { method }\end{array}$ & $\begin{array}{c}\text { Sheather's } \\
\text { sucrose } \\
\text { floatation } \\
\text { method }\end{array}$ & $\begin{array}{c}\text { Direct } \\
\text { iodine } \\
\text { smear }\end{array}$ \\
& & & & \\
& & 67.8 & 54.4 & 11.1 \\
& Ancylostoma sp. & 27.8 & 15.6 & 4.4 \\
& Toxocara canis & 3.3 & 15.6 & 12.2 \\
& Spirocerca lupi & 11.1 & 7.8 & 1.1 \\
& Strongyloides sp. & 12.2 & 8.9 & 1.1 \\
& Toxascaris sp. & 12.2 & 8.9 & 3.3 \\
& Trichuris vulpis & 5.6 & 4.4 & 1.1 \\
& Capillaria aerophyla & 5.1 & 1.1 & - \\
Protozoans & Trematode sp. & 1.1 & 6.7 & 20.0 \\
& Entamoeba sp. & 2.2 & - & 12.2 \\
& Blastocystis sp. & - & 3.3 & 3.3 \\
& Isospora sp. & 3.3 & 1.1 & 3.3 \\
& Giardia sp. & - & - & - \\
Cyclospora sp. & 1.1 & &
\end{tabular}

except cysts by Isospora $\mathrm{sp}$. were successfully detected by iodine smear preparation. Prevalence of detection of cysts of Isospora sp. (3\%) was similar by all three methodologies used.

\section{Factors affecting the prevalence of infection}

More female dogs $(91.5 \%)$ harboured GI parasites than male dogs $(88.4 \%)$ but this difference was not statistically significant (chi square $p>0.05$ ) (Table 4$)$. Percentages of infected males and females varied between the three dog categories. Although the overall difference in prevalence of infection between males and females was not significant, among the stray dogs all the females were infected, which significantly differed from that of the males $\left(\chi^{2}=5.893 \mathrm{p}=0.015\right.$; Table 4$)$.

There was no significant difference in infections by GI parasites in puppies $(91.4 \%)$ and adults $(90.9 \%)$ but puppies carried more protozoan infections than helminths compared to the adults. Protozoan prevalence was significantly higher in puppies $(51.4 \%)$ compared to adults $\left(29.0 \% ; \chi^{2}=4.33 ; p=0.033\right.$; Table 5). Except Ancylostoma sp. all other species of helminths were found in higher proportions in puppies than in adults (Table 5). Toxascaris $\mathrm{sp}$. infections were significantly higher among the stray puppies $(57.1 \%)$ than in stray adults $(17.4 \%)$; $\left(\chi^{2}=4.337, \mathrm{p}=0.037\right)$. Among the $90 \mathrm{dogs}, 36(40 \%)$ had skin lesions. Although almost all of the dogs who possessed skin lesions were infected by at least a single

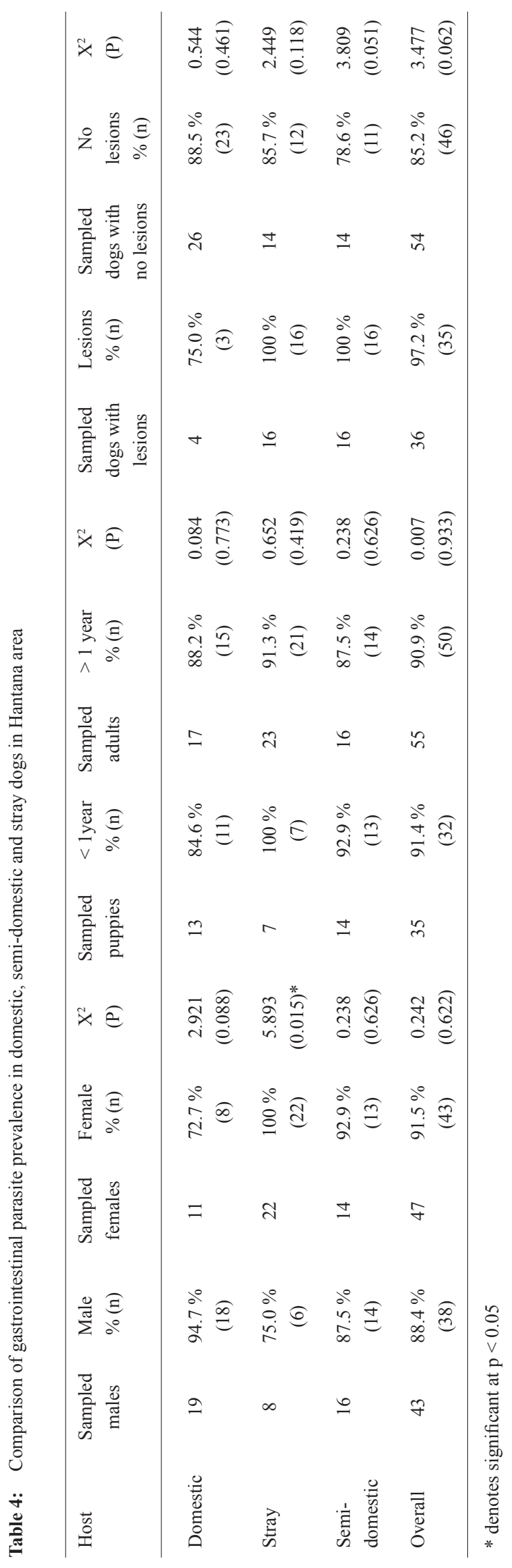

June 2013

Journal of the National Science Foundation of Sri Lanka 41 (2) 
Table 5: Prevalence of helminths and prortozoan infections among the different categories of dogs

\begin{tabular}{|c|c|c|c|c|c|c|c|c|c|}
\hline & \multirow{2}{*}{$\begin{array}{l}\text { Parasite } \\
\text { species }\end{array}$} & \multicolumn{2}{|c|}{ Gender (n) } & \multicolumn{2}{|c|}{ Age (n) } & \multicolumn{2}{|c|}{ Skin lesions (n) } & \multicolumn{2}{|c|}{ Breed (n) } \\
\hline & & Male & Female & Puppies & Adults & $\begin{array}{c}\text { With skin } \\
\text { lesions }\end{array}$ & $\begin{array}{c}\text { Without } \\
\text { skin lesions }\end{array}$ & Pure & Mixed \\
\hline \multirow[t]{9}{*}{ Helminths } & Ancylostoma sp. & $\begin{array}{c}67.4 \% \\
(29)\end{array}$ & $\begin{array}{c}74.5 \% \\
(35)\end{array}$ & $\begin{array}{c}68.6 \% \\
(24)\end{array}$ & $\begin{array}{c}76.4 \% \\
(42)\end{array}$ & $\begin{array}{c}97.2 \% \\
(35)\end{array}$ & $\begin{array}{c}55.6 \% \\
(30)\end{array}$ & $\begin{array}{c}50.0 \% \\
(8)\end{array}$ & $\begin{array}{c}71.4 \% \\
(10)\end{array}$ \\
\hline & Toxocara canis & $\begin{array}{c}37.2 \% \\
(16)\end{array}$ & $\begin{array}{c}25.5 \% \\
(12)\end{array}$ & $\begin{array}{c}40.0 \% \\
(14)\end{array}$ & $\begin{array}{c}25.5 \% \\
(14)\end{array}$ & $\begin{array}{c}41.7 \% \\
(15)\end{array}$ & $\begin{array}{c}24.1 \% \\
(13)\end{array}$ & $\begin{array}{c}37.5 \% \\
(6)\end{array}$ & $\begin{array}{c}28.6 \% \\
(4)\end{array}$ \\
\hline & Spirocerca lupi & $\begin{array}{c}25.6 \% \\
(11)\end{array}$ & $\begin{array}{c}19.0 \% \\
(9)\end{array}$ & $\begin{array}{c}28.6 \% \\
(10)\end{array}$ & $\begin{array}{c}20.0 \% \\
(11)\end{array}$ & $\begin{array}{c}25.0 \% \\
(9)\end{array}$ & $\begin{array}{c}18.5 \% \\
(10)\end{array}$ & $\begin{array}{c}6.3 \% \\
(1)\end{array}$ & $\begin{array}{c}50.0 \% \\
(7)\end{array}$ \\
\hline & Strongyloides sp. & $\begin{array}{c}9.3 \% \\
(4)\end{array}$ & $\begin{array}{c}14.9 \% \\
(7)\end{array}$ & $\begin{array}{c}14.3 \% \\
(5)\end{array}$ & $\begin{array}{c}12.7 \% \\
(7)\end{array}$ & $\begin{array}{c}25.0 \% \\
(9)\end{array}$ & $\begin{array}{c}1.9 \% \\
(1)\end{array}$ & - & - \\
\hline & Toxascaris sp. & $\begin{array}{c}4.7 \% \\
(2)\end{array}$ & $\begin{array}{c}17.0 \% \\
(8)\end{array}$ & $\begin{array}{c}17.1 \% \\
(6)\end{array}$ & $\begin{array}{c}9.1 \% \\
(5)\end{array}$ & $\begin{array}{c}13.8 \% \\
(5)\end{array}$ & $\begin{array}{c}7.4 \% \\
(4)\end{array}$ & - & - \\
\hline & Trichuris vulpis & $\begin{array}{c}4.7 \% \\
(2)\end{array}$ & $\begin{array}{c}23.4 \% \\
(11)\end{array}$ & $\begin{array}{c}14.3 \% \\
(5)\end{array}$ & $\begin{array}{c}12.7 \% \\
(7)\end{array}$ & $\begin{array}{c}16.7 \% \\
(6)\end{array}$ & $\begin{array}{c}9.3 \% \\
(5)\end{array}$ & - & - \\
\hline & C. aerophyla & $\begin{array}{c}2.3 \% \\
(1)\end{array}$ & $\begin{array}{c}8.5 \% \\
(4)\end{array}$ & $\begin{array}{c}8.6 \% \\
(3)\end{array}$ & $\begin{array}{c}3.6 \% \\
(2)\end{array}$ & $\begin{array}{c}8.3 \% \\
(3)\end{array}$ & $\begin{array}{c}9.3 \% \\
(5)\end{array}$ & - & - \\
\hline & Trematode sp. & $\begin{array}{c}2.3 \% \\
(1)\end{array}$ & $\begin{array}{c}2.1 \% \\
(1)\end{array}$ & $\begin{array}{c}2.9 \% \\
(1)\end{array}$ & $\begin{array}{c}1.8 \% \\
(1)\end{array}$ & $\begin{array}{c}5.6 \% \\
(2)\end{array}$ & - & - & - \\
\hline & Total $^{1}$ & $\begin{array}{c}76.7 \% \\
(33)\end{array}$ & $\begin{array}{c}91.5 \% \\
(43)\end{array}$ & $\begin{array}{c}82.9 \% \\
(29)\end{array}$ & $\begin{array}{c}85.5 \% \\
(47)\end{array}$ & $\begin{array}{c}97.2 \% \\
(35)\end{array}$ & $\begin{array}{c}75.9 \% \\
(41)\end{array}$ & $\begin{array}{c}62.5 \% \\
(10)\end{array}$ & $\begin{array}{c}92.9 \% \\
(13)\end{array}$ \\
\hline \multirow[t]{6}{*}{ Protozoans } & Cyclospora sp. & $\begin{array}{c}2.3 \% \\
(1)\end{array}$ & - & $\begin{array}{c}2.9 \% \\
(1)\end{array}$ & - & - & $\begin{array}{c}2.8 \% \\
(1)\end{array}$ & $\begin{array}{c}6.3 \% \\
(1)\end{array}$ & - \\
\hline & Blastocystis sp. & $\begin{array}{c}16.3 \% \\
(7)\end{array}$ & $\begin{array}{c}8.5 \% \\
(4)\end{array}$ & $\begin{array}{c}17.1 \% \\
(6)\end{array}$ & $\begin{array}{c}9.1 \% \\
(5)\end{array}$ & $\begin{array}{c}11.1 \% \\
(4)\end{array}$ & $\begin{array}{c}16.7 \% \\
(6)\end{array}$ & $\begin{array}{c}25.0 \% \\
(4)\end{array}$ & $\begin{array}{c}14.3 \% \\
(2)\end{array}$ \\
\hline & Giardia sp. & 0.0 & $\begin{array}{c}6.4 \% \\
(3)\end{array}$ & $\begin{array}{l}5.7 \% \\
(2)\end{array}$ & $\begin{array}{c}1.8 \% \\
(1)\end{array}$ & $\begin{array}{c}2.8 \% \\
(1)\end{array}$ & $\begin{array}{c}3.7 \% \\
(2)\end{array}$ & - & - \\
\hline & Entamoeba sp. & $\begin{array}{c}23.3 \% \\
(10)\end{array}$ & $\begin{array}{c}25.5 \% \\
(12)\end{array}$ & $\begin{array}{l}25.7 \% \\
(9)\end{array}$ & $\begin{array}{c}18.2 \% \\
(10)\end{array}$ & $\begin{array}{c}16.7 \% \\
(6)\end{array}$ & $\begin{array}{c}16.7 \% \\
(9)\end{array}$ & $\begin{array}{c}18.8 \% \\
(3)\end{array}$ & $\begin{array}{c}28.6 \% \\
(4)\end{array}$ \\
\hline & Isospora $\mathrm{sp}$. & $\begin{array}{c}2.3 \% \\
(1)\end{array}$ & $\begin{array}{c}12.8 \% \\
(6)\end{array}$ & $\begin{array}{c}11.4 \% \\
(4)\end{array}$ & $\begin{array}{c}5.5 \% \\
(3)\end{array}$ & $\begin{array}{c}13.8 \% \\
(5)\end{array}$ & $\begin{array}{c}3.7 \% \\
(2)\end{array}$ & - & - \\
\hline & Tota $^{1}$ & $\begin{array}{c}34.9 \% \\
(15)\end{array}$ & $\begin{array}{c}42.6 \% \\
(20)\end{array}$ & $\begin{array}{c}51.4 \% \\
(18)\end{array}$ & $\begin{array}{c}29.0 \% \\
(16)\end{array}$ & $\begin{array}{c}44.4 \% \\
(16)\end{array}$ & $\begin{array}{c}31.5 \% \\
(17)\end{array}$ & $\begin{array}{c}43.8 \% \\
(7)\end{array}$ & $\begin{array}{c}35.7 \% \\
(5)\end{array}$ \\
\hline
\end{tabular}

${ }^{1}$ Percentages were calculated by dividing the number of positive dogs by the total number of individuals in the group.

parasite $(97.2 \%)$, there was no significant difference in the prevalence of GI infections in dogs with or without skin lesions $(85.2 \%)$. However, dogs with skin lesions harbouring helminth infections were significantly higher than those without skin lesions $\left(\chi^{2}=7.4624, p=0.006\right)$.

Overall parasitic infections were more common among the mixed bred dogs $(92.9 \%)$ than with pure bred dogs $(81.3 \%)$ and in dogs that were not dewormed regularly $(91.7 \%)$ compared to the regularly de-wormed $(83.3 \%)$. However, these differences were not statistically significant (chi square test $\mathrm{p}>0.05$ ). Of the domestic dogs, 16 were pure bred and 14 were mix bred dogs. These pure breeds included Boxer, Rottweiler,
Dachshund, German Shepherd, Pekingese, Bullmastiff and Dalmatian. Among the domestic dogs, helminth infections were significantly more prevalent in mixed bred dogs $(92.9 \%)$ compared to the pure bred dogs $(62.5 \% ; p=0.049)$ but the protozoan prevalence was not significant among mixed bred $(35.7 \%)$ and pure bred dogs $(43.8 \%)$.

None of the dog owners claimed that they feed raw or undercooked meat or fish to their dogs or that their dogs eat carcasses of dead animals except beetles or other insects that come into the house. The questionnaire data showed that the majority of the dog owners did not know about the GI parasites in dogs, the mechanisms of 
transmission, the risk factors for zoonotic infections, and specific prophylactic measures.

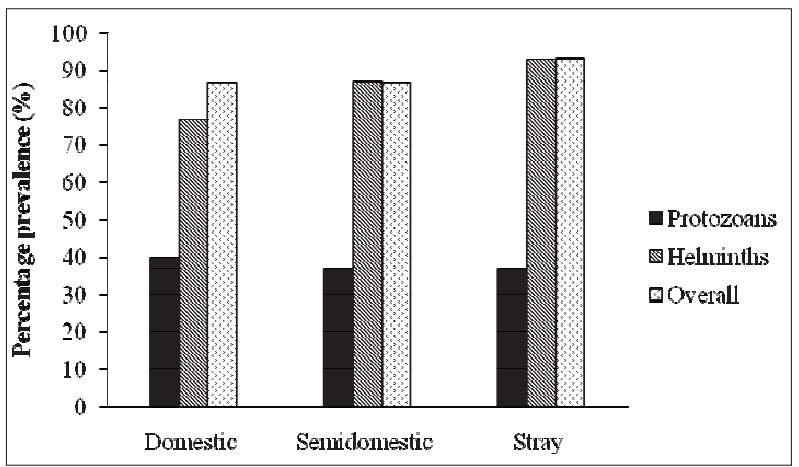

Figure 2: Percentage prevalence of gastrointestinal parasites in domestic, semi-domestic and stray dogs $(\mathrm{n}=90 \mathrm{dogs}, 30$ from each group)

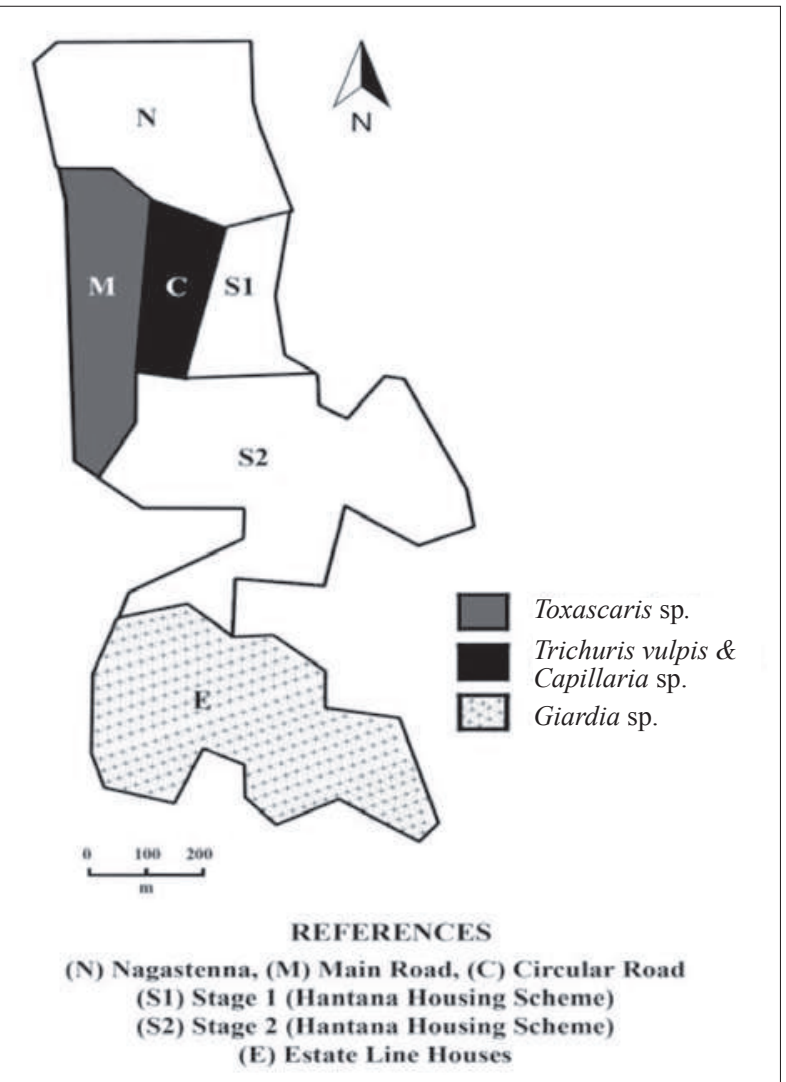

Figure 3: Map showing areas where Toxascaris sp., Trichuris vulpis, Capillaria aerophyla and Giardia sp. occurred in Hantana.

\section{Distribution of parasites}

When the spatial distribution of the parasites was considered, T. canis, T. vulpis, C. aerophyla, Toxascaris sp. and Giardia sp. had a heterogeneous distribution (Figure 3). Toxocara canis had a wider distribution and Giardia sp. was confined to the estate line housed area. T. vulpis and C. aerophyla were only found in the lower part of the Circular Road inside the Hantana Housing Scheme. Toxascaris sp. was highly prevalent along the main road from IFS to the beginning of the Circular Road (Figure 3).

\section{DISCUSSION}

A high overall prevalence $(90 \%)$ of GI parasites were found in dogs in the Hanata area. There was no significant difference in the prevalence of infections among the stray dogs, domestic and semi-domestic dogs, irrespective of worm treatments and hygiene levels of the domestic dogs. However, the intensity of infection was low in domestic dogs and they harboured fewer species of helminths than the other two groups. More domestic dogs were infected with protozoan parasites but the intensity of helminth infections as well as the number of helminth species found in domestic dogs was low. This could be due to the administration of antihelminthics like Pyrantel pamoate, which are commonly used to control helminths, but not protozoans. These findings are consistent with those of Bugg et al. (1999) where they reported dominance of GI protozoa affecting urban dogs in Perth, Australia. Gastrointestinal protozoans are unaffected by the antihelminthics in common use. Bugg et al. (1999) suggest another possibility that intestinal protozoa to be high as they can easily colonize the niche vacated by the helminths such as $T$. canis and D. caninum. Effective drugs against enteric protozoans such as Metronidazole $\AA$ (Dunsmore \& Shaw, 1990) have not been given to any of the domestic dogs examined.

In the present study, a strong species association was observed between Ancylostoma sp. and T. canis. Visco et al. (1977) and Fontanarrosa et al. (2006) reported a strong positive association between Ancylostoma sp. and T. vulpis in North America. The presence of one parasite species may enhance the presence of the other species since the dogs that are with higher parasite intensity are known to be with less immunity (Fontanarrosa et al., 2006). The types of helminth and protozoan species found in the present study were similar to those reported in earlier surveys of dogs in Sri Lanka (Senadhira, 1967; De Alwis, 2000) although their prevalence varied. 
Consistent with previous finding of Seneviratne (1955), hook worm Ancylostoma sp. was the most common and widespread parasite species in the Hantana area as well. Dogs are known to harbour many species of Ancylostoma namely, A. braziliense, A. ceylanicum and A. caninum that also infect humans (Senadhira, 1967a; Schad \& Banwell, 1990; Schad, 1991; Dissanaike, 1995). The most dangerous disease for dogs found in the study is by $S$. lupi which cause death due to aortic rupture.

Out of the 13 parasite species reported in this study, T. canis (Fernando et al., 1970), Ancylostoma sp. (Dissanaike, 1995) and Giardia sp. are known zoonoses in Sri Lanka. Moreover, out of the other parasites recorded, Strongyloides sp., Toxascaris sp., T. vulpis, C. aerophyla, Blastocystis sp., Entamoeba sp. and Isospora sp. are known to be zoonoses around the world (Dunsmore \& Shaw, 1990). Among domestic dogs $S$. lupi infection was higher than in semi-domestic and stray dog categories. This could be because domestic dogs eat coprophagous beetles found inside houses and these beetles act as an intermediate host for the parasite, and therefore a source of infection to the dog (Dunsmore \& Shaw, 1990; Marquardt et al., 2000). The most dangerous zoonotic disease that could infect humans found in the survey is by $T$. canis, which causes both visceral larvae migrans and ocular larvae migrans in humans. Toxascaris leonina has been previously reported in cats and wild canids (Seneviratne, 1955). Seneviratne (1955) found this in leopards in Kandy and stated the possibility of it infecting dogs as well. This could be the first recording of Toxascaris sp. in dogs in Sri Lanka. It could have been transmitted by either cats or wild canids such as fishing cat (Prionailurus viverrinu) or leopard (Panthera pardus kotiya) in Hantana. This indicates that transfer of parasites from wild animals to domestic animals is a possibility.

Studies have recorded many GI trematodes such as Alaria nasuae in Mexico (Shoop et al., 1989), Alaria arisaemoides in Saskatchuwan, Canada (Allen \& Mills, 1971), and Mesostephanus appendiculatus, Mesostephanus milvi, Mesostephanus fajardensis, Echinochasmus liliputanus, Heterophyes dispar, and Pygidiopsis genata in Egypt (El-Gayar, 2007) from domestic and stray dogs. In the present study, only one type of trematode eggs was recorded at very low prevalence $(1.1 \%)$ and low intensity $(\mathrm{EPG}=0.7)$. This could be because of the methods that were used to isolate and identify parasites and eggs (salt floatation, Sheather's sucrose floatation) may have limitations in picking up trematode eggs. If sedimentation technique had been carried out, which is specifically for trematode egg isolation, it would give a better understanding of the trematode infections of the dog population in the Hantana area.

More females harboured GI parasites than males especially among the stray dogs. The underlying cause for this could be the immune suppression of females especially during pregnancy and lactation. As in previous studies done in various parts of the world (Hoskins et al., 1982; Maizels \& Meghji, 1984; Oliveira-Sequeria et al., 2002) T. canis was also found to be higher among male dogs in the Hantana area. Females in late lactation are likely to be infected but that the infection does not usually persist after the pups are weaned and also after the mating behaviours such as roaming of males are over (Kirkpatrick, 1988). Age was found to exert a less influence on the prevalence of some parasites, for example T. canis (De Alwis, 2000; McGlade et al., 2003; le Nobel et al., 2004; Martinez-Carrasco et al., 2007; Palmer et al., 2008). Mixed bred dogs were more infected by helminth parasites such as $S$. lupi than pure bred dogs. However, since pure bred dogs were being raised by socio-economically higher residents (Traub et al., 2002), and as those in the Hantana area are raised mostly for husbandry purposes, they received regular veterinary care and were kept under strict hygienic conditions. The results of the present study are consistent with those of Fontanarrosa et al. (2006). Prevalence of Ancylostoma $\mathrm{sp}$. and Strongyloides sp. were highly significant among the dogs with skin lesions showing that hookworm dermatitis and higher penetration levels of larvae via scaling skin.

Distribution of the parasite species was not even in the Hantana area. T. canis, T. vulpis, C. aerophyla, Toxascaris sp. and Giardia sp. were confined to certain areas in Hantana, suggesting that even among the same dog category, isolation as groups according to their territorial behaviour is common.

Three methods namely, modified salt floatation method, Sheather's sucrose floatation method, and preparation of iodine smears were used to isolate parasites with varying sensitivity. No tapeworm proglottids, Taenia eggs or Cryptosporidium oocysts were detected in any of the samples. The prevalence of tapeworm and protozoans may have been underestimated because the centrifugation-floatation method is not suitable for the detection of cestodes and protozoans (Sherding, 1983; Robertson, 2002; McGlade et al., 2003; Claerebout \& Thompson et al., 2009). Although tapeworm eggs were rare in the present study, there is an earlier record by Dissanaike (1957) of an adult tapeworm Echinococcus granulosus from a dog in the Kandy District. However, since this was reported more than 50 years ago, the situation may be different now. The zinc concentration 
method has been recommended as a better method for isolating Giardia compared to the sucrose floatation method used in the current study (McGlade et al., 2003).

Dogs in the Hantana area harbour many zoonotic parasites to which the residents are constantly exposed to. Administration of antihelminthics accompanied by regular faecal examination would provide an effective strategy in controlling GI parasites of domestic dogs.

\section{REFERENCES}

1. Abo-Shehada M.N. \& Ziyadeh Y. (1991). Prevalence of endoparasites in dog faecal deposits in Jordan. Journal of Helminthology 65: $313-314$.

2. Allen J.R. \& Mills J.H. (1971). Alaria arisaemoides in Saskatchewan dogs. Canadian Veterinary Journal 12(1): $24-28$.

3. Anene B.M., Nnaji T.O. \& Chime A.B. (1996). Intestinal parasitic infections of dogs in the Nsukka area of Enugu State, Nigeria. Preventive Veterinary Medicine 27: 89 94.

4. Asano K., Suzuki K., Matsumoto T., Sakai T. \& Asano R. (2004). Prevalence of dogs with intestinal parasites in Tochigi, Japan in 1979, 1991 and 2002. Veterinary Parasitology 120: 243 - 248.

5. Bianciardi P., Papini R., Giuliani G. \& Cardini G. (2004). Prevalence of Giardia antigen in stool samples from dogs and cats. Revue de Medecine Veterinaire 155: 417 - 421.

6. Bridger K.E. \& Whitney H. (2009). Gastrointestinal parasites in dogs from the island of St. Pierre off the south coast of Newfoundland. Veterinary Parasitology 162: 167 -170 .

7. Bugg R.J., Robertson I.D., Elliot A.D. \& Thompson R.C. (1999). Gastrointestinal parasites of urban dogs in Perth, Western Australia. Veterinary Journal 157: 295 - 301.

8. Capelli G., Paoletti B., Iorio R., Frangipane Di Regalbono A., Pietrobelli M., Bianciardi P. \& Giangaspero A. (2003). Prevalence of Giardia spp. in dogs and humans in Northern and Central Italy. Parasitology Research 90: S154 - S155.

9. Chattha M.A., Aslam A., Rehman Z.U., Khan J.A. \& Avais M. (2009). Prevalence of Toxocara canis in dogs and its effects on various blood parameters in Lahore (Pakistan). The Journal of Animal and Plant Sciences 19(2): 71 - 73.

10. Claerebout E., Casaert S., Dalemans A.C., De Wilde N., Levecke B., Vercruysse J. \& Geurden T. (2009). Giardia and other intestinal parasites in different dog populations in Northern Belgium. Veterinary Parasitology 161: 41 - 46.

11. De Alwis T.M.D.R. (2000). A survey of endoparasitic zoonoses in stray dogs at selected locality in Polonnaruwa District. $M S c$ thesis, pp. 8 - 42. Department of Pathobiology, Faculty of Veterinary Medicine and Animal Sciences, University of Peradeniya, Peradeniya.

12. Dissanaike A.S. (1957). Some preliminary observations on Echinicoccus infection in local cattle and dogs. Ceylon Medical Journal 4(2): 69 - 75 .
13. Dissanaike A.S. (1961). On some helminths of dogs in Colombo and their bearing on human infections, with a description of a new trematode Heterophyopsis yehi Nov. (Heterophyidae). Ceylon Journal of Medical Sciences 10: $1-12$.

14. Dissanaike A.S. (1995). Uncommonly reported parasitic infections of childhood and parasites of the future. Ceylon Journal of the Child Health 24: $1-8$.

15. Dunsmore J.D. \& Shaw S.E. (1990). Clinical Parasitology of Dogs, pp. 1 - 145. Post Graduate Foundation in Veterinary Science, The University of Sydney, Australia.

16. Eguı'a-Aguilar P., Cruz-Reyes A. \& Martı'nez-Maya J.J. (2005). Ecological analysis and description of the intestinal helminths present in dogs in Mexico City. Veterinary Parasitology 127: 139 - 146.

17. El-Gayar A.K. (2007). Studies on some trematode parasites of stray dogs in Egypt with a key to the identification of intestinal trematodes of dogs. Veterinary Parasitology 144: $360-365$.

18. Fernando S.T., Vasudevan B., Hamza M.H.M., Panditha Gunawardena I.K.T. \& Samarasinghe H.T. (1970). Precipitin reaction in monkeys (Macaca sinica) experimentally infected with Toxocara canis and children with visceral larvae migrans syndrome. Journal of Comparative Pathology 80: 407 - 414.

19. Fok E., Szatma'ri V., Busa'k K. \& Rosgonyi F. (2001). Prevalence of intestinal parasites in dogs in some urban and rural areas of Hungary. Veterinary Questions 23: 96 -98 .

20. Fontanarrosa M.F., Vezzani D., Basabe J. \& Eiras D.F. (2006). An epidemiological study of gastrointestinal parasites of dogs from Southern Greater Buenos Aires (Argentina): age, gender, breed, mixed infections, and seasonal and spatial patterns. Veterinary Parasitology 136: $283-295$.

21. Habluetzel A., Traldi G., Ruggieri S., Attili A.R., Scuppa P., Marchetti R., Menghini G. \& Esposito F. (2003). An estimation of Toxocara canis prevalence in dogs, environmental egg contamination and risk of human infection in the Marche region of Italy. Veterinary Parasitology 113: 243 - 252.

22. Hackett T. \& Lappin M.R. (2003). Prevalence of enteric pathogens in dogs of north-central Colorado. Journal of the American Animal Hospital Association 39: 52 - 56.

23. Hoskins J.D., Malone J.B., Smith P.H. \& Uhl S.A. (1982). Prevalence of parasitism diagnosed by fecal examination in Louisiana dogs. American Journal of Veterinary Research 43: 1106 - 1109.

24. Itoh N., Kanai K., Hori Y., Hoshi F. \& Higuchi S.(2009). Prevalence of Giardia intestinalis and other zoonotic intestinal parasites in private household dogs of the Hachinohe area in Aomori prefecture, Japan in 1997, 2002 and 2007. Journal of Veterinary Science 10(4): 305 -308 .

25. Kagira J.M. \& Kanyari P.W.N.(2001). Parasitic diseases as causes of mortality in dogs in Kenya: a retrospective study of 351 cases (1984-1998). Israel Journal of Veterinary Medicine 1: 56 - 57.

26. Kirkpatrick C.E. (1988). Epizootiology of endoparasitic infections in pet dogs and cats presented to a veterinary 
teaching hospital. Veterinary Parasitology 30: 113 - 124.

27. le Nobel W.E., Robben S.R.M., Do“ pfer D., Hendrikx W.M.L., Boersema J.H., Fransen F. \& Eysker M. (2004). Infections with endoparasites in dogs in Dutch animal shelters. Tijdschr Diergeneesk 129: 40 - 44.

28. Maizels R.M. \& Meghji M. (1984). Repeated patent infection of adult dogs with Toxocara canis. Journal of Helminthology 58: 327 - 333.

29. Marquardt W.C., Demaree R.S. \& Grieve R.B. (2000). Parasitology and Vector Biology, $2^{\text {nd }}$ edition, pp. 451 453. Academic Press. California. USA.

30. Mart1'nez-Carrasco C., Berriatua E., Garijo M., Martı'nez J., Alonso D. \& Ruiz de Yba'ñ ez (2007). Epidemiological study of non-systemic parasitism in dogs in Southeast Mediterranean Spain assesses by coprological and post-mortem examination. Zoonoses Public Health 54: $195-203$.

31. McGlade T.R., Robertson I.D., Elliot A.D. \& Thompson R.C.A. (2003). High prevalence of Giardia detected in cats by PCR. Veterinary Parasitology 110: $197-205$.

32. Minnaar W.N., Krecek R.C. \& Fourie L.J. (2002). Helminths in dogs from a peri-urban resource-limited community in Free State Province, South Africa. Veterinary Parasitology 107: 343 - 349.

33. Oliveira-Sequeira T.C.G., Amarante A.F.T., Ferrari T.B. \& Nunes L.C. (2002). Prevalence of intestinal parasites in dogs from São Paulo State, Brazil. Veterinary Parasitology 103: $19-27$.

34. Palmer C.S., Thompson R.C.A., Traub R.J., Res R. \& Robertson I.D. (2008). National study of the gastrointestinal parasites of dogs and cats in Australia. Veterinary Parasitology 151: 181 - 190.

35. Ramı'rez-Barrios R.A., Barboza-Mena G., Munoz J., Angulo- Cubillan F., Hernandez E., Gonzalez F. \& Escalona F. (2004). Prevalence of intestinal parasites in dogs under veterinary care in Maracaibo, Venezuela. Veterinary Parasitology 121: $11-20$.

36. Rajapakse R.P.V.J., Vasanthathilake V.W.S.M., Lloyd S. \& Fernando S.T. (1992). Collection of eggs and hatching and culturing second-stage larvae of Toxocara vitulorum in vitro. Journal of Parasitology 78 (6): 1090 - 1092.

37. Robertson I.D., Irwin P.J., Lymbery A.J. \& Thompson R.C.A. (2000). The role of companion animals in the emergence of parasitic zoonoses. International Journal of Parasitology 30: 1369 - 1377.

38. Robertson I. D. \& Thompson R.C.A. (2002). Enteric parasitic zoonoses of domesticated dogs and cats. Clinical
Microbiology and Infection 4: $867-873$.

39. Scaramozzino P., Cave D.D., Bettilli F., D’Orazi C., Spaziani A., Mazzanti S., Scholl F. \& Liberato C.D. (2009). A study of the prevalence and genotypes of Giardia duodenalis infecting kenneled dogs. The Veterinary Journal 182: 231 - 234.

40. Schad G.A. (1991). The parasite. Hookworm Infections. (ed. P.A.J. Ball), pp. 15 - 49. Elsevier Science Publishers, Amsterdam, The Netherlands.

41. Schad G.A. \& Banwell J.G. (1990). Hookworms. Tropical and Geographical Medicine (ed. A.A.F. Mahmoud), pp. 379 - 393. McGraw-Hill Book Co. New York, USA.

42. Senadhira M.A.R. (1967 a). The parasites of Ceylon iv. Nematode. Ceylon Veterinary Journal 15: 83 - 99.

43. Senadhira M.A.P. (1967 b). The parasites of Ceylon ii, Trematoda. Ceylon Veterinary Journal 15: 33 - 41.

44. Seneviratna P. (1955). A check list of helminths in the Department of Veterinary Pathology, University of Ceylon, Peradeniya. Ceylon Veterinary Journal 3: 32 - 37.

45. Seneviratna P. (1962). Some infectious diseases of dogs in Ceylon and the routine therapeutic or preventive measures that may be adopted against them. Probang 7(1): $28-35$.

46. Seneviratna P., Fernando S.T. \& Dhanapala S.B. (1965). Disophenol in the treatment of Spirocerca lupi infection in dogs. Veterinary Record 77: 798 - 799.

47. Sherding R.G. (1983). Diseases of the small bowel. Textbook of Veterinary Internal Medicine: Diseases of the Dog and Cat (ed. S.J. Ettinger), volume 2, pp. 1312 1319. Saunders, Philadelphia, USA.

48. Shoop W.L., Salazar M.A., Vega C.S., Font W.F. \& Infante F. (1989). Alaria nasuae (Trematoda: Diplostomidae) from domestic dogs. Parasitology 75(2): 325 - 327.

49. Soriano S.V. (2010). A wide diversity of zoonotic intestinal parasites infects urban and rural dogs in Neuquén, Patagonia, Argentina. Veterinary Parasitology 167: $81-85$.

50. Stallbaumer M. (1987). The prevalence and epidemiology of cestodes in dogs in Clwyd, Wales. II. Hunting dogs. Annals of Tropical Medicine and Parasitology 81: $43-47$.

51. Traub R.J., Robertson I.D., Irwin P.J., Mencke N. \& Thompson R.C.A. (2002). Canine gastrointestinal parasitic zoonoses in India. Trends in Parasitology 21: $42-48$.

52. Visco R.J., Corwin R.M. \& Selby L.A. (1977). Effect of age and sex on the prevalence of intestinal parasitism in dogs. Journal of the American Veterinary Medical Association 170: 835 - 837. 